\title{
Investigation of the phase formation and dielectric properties of Bi7Ta3O18
}

\begin{abstract}
Polycrystalline Bi7Ta3O18 was synthesised at the firing temperature of $950{ }^{\circ} \mathrm{C}$ over $18 \mathrm{~h}$ via conventional solid state method. It crystallised in a monoclinic system with space group $\mathrm{C} 2 / \mathrm{m}, \mathrm{Z}=4$ similar to that reported diffraction pattern in the Inorganic Crystal Structure Database (ICSD), 1-89-6647. The refined lattice parameters were $a=34.060$ (3) $\AA, b=7.618$ (9) $\AA, c=6.647$ (6) $\AA$ with $\breve{U}=\mathrm{J}=90^{\circ}$ and $\mathrm{b}=109.210$ (7), respectively. The intermediate phase was predominantly in high-symmetry cubic structure below $800{ }^{\circ} \mathrm{C}$ and finally evolved into a low-symmetry monoclinic structured, Bi7Ta3O18 at $950{ }^{\circ} \mathrm{C}$. The sample contained grains of various shapes with different orientations in the size ranging from $0.33 \ddot{I} 22.70 \mathrm{\varepsilon m}$. The elemental analysis showed the sample had correct stoichiometry with negligible Bi2O3 loss. Bi7Ta3O18 was thermally stable and it exhibited a relatively high relative permittivity, 241 and low dielectric loss, 0.004 at room temperature, $\sim 30{ }^{\circ} \mathrm{C}$ and frequency of $1 \mathrm{MHz}$.
\end{abstract}

Keyword: Ceramics; Sintering; Powder diffraction; Dielectric properties 